\title{
Finite Element Analysis of Contact Stress for Crowned Cylindrical Roller Bearings of Railway Passenger Cars
}

\author{
Chunhui YANG ${ }^{1}$ and Changliang ZHANG \\ School of Mechatronics \& Vehicle Engineering, East China Jiaotong University, \\ Jiangxi, Nanchang 330013, China
}

\begin{abstract}
The finite element model of NJP3226X1 cylindrical roller bearings was established by ABAQUS software, and the contact stress distribution of three kinds of modification curve(linear, circular-arc, logarithmic) were compared. The results showed that the maximal contact stress of logarithmic modified roller is the minimum, its stress distribute uniformly, and obvious stress concentration phenomenon does not exist, next is circular-arc modified roller, which stress at the two ends is too small and the stress in the middle is large, linear roller has the highest contact stress, and there is an obvious stresses concentration phenomenon at both ends. Through the analysis of the contact stress distribution of the logarithmic shaped roller under different repair quantities, the reasonable repair quantities are obtained.
\end{abstract}

Keywords. Railway passenger cars, cylindrical roller bearing, modification, finite element analysis

\section{Introduction}

The axle box bearing is one of the important assembly of electric multiple unit (EMU). Since 2013, cylindrical roller bearings have been applied in china railway high-speed train (CRH) [1]. The service life of cylindrical roller bearings in China is only $1 / 12$ $1 / 8$ of similar products in developed countries, the failure rate of roller is $80 \%$ and $34.5 \%$ respectively. The "edge effect" of the linear cylindrical roller bearing greatly increases the bearing wear and reduces the fatigue life of the bearing. Therefore, many experts and scholars have done a lot of research on how to solve this "edge effect". The application of the straight generatrix modification technology is an effective method to reduce this phenomenon [2]. Application of shape modification technology can effectively improve the stress distribution in rolling contact area, decrease or eliminate the stress concentration at the roller edge, and reduce the vibration and noise of bearings, and increase bearing life. The modification curve of cylindrical roller bearing adopts circular-arc, logarithmic, etc. As the contact problems of Lundberg logarithmic roller and ring, Chen Xiaoyang used influence coefficient method to analysis and gave corresponding crown design methods [3]. The stress distribution of straight generatrix, circular arc and logarithmic profile modification has been compared by finite element

\footnotetext{
${ }^{1}$ Yang Chunhui, Zhang Changliang, School of Mechatronics \& Vehicle Engineering, East China Jiaotong University, 808 Shuanggang East Street, Nanchang, Jiangxi, CHINA;E-mail: 755518122@qq.com.
} 
method $[4,5]$. It was concluded that the edge of straight generatrix roller was easy to produce stress concentration, and the arc crown curve could effectively reduce the edge stress under light load and medium load, but the edge stress still existed in the case of heavy load, and the edge effect can be completely eliminated by using logarithmic modification roller [6]. Wei Yangang put forward the asymmetric shape modification method [7], unsymmetric shape modification could not only avoid "edge effect" and could also overcome "leaning load effect". The contact load distribution between the roller and the inner and outer raceways of the cylindrical roller bearing of the railway passenger is analyzed by romax method [8]. The influence of roller convexity excursion of high-speed cylindrical roller bearing on roller's dynamic characteristics is studied[9].Yang Fan et al. compared the influence of different roller contour curves and convex measures on the contact stress and fatigue life of cylindrical roller bearings [10]. B. Schauder used the half space mechanics theory to calculate the contact stress distribution between the roller and the inner and outer rings [11]. The application of crown technology can effectively improve the pressure distribution, reduce or eliminate the pressure concentration, reduce the vibration and noise of the bearing and improve the service life of the bearing[12,13]. It is difficult to solve the stress and strain distribution in the contact area between roller and raceway by Hertz theory, and the finite element method is undoubtedly an economical and effective method.

In this paper, the finite element model of NJP3226X1 cylindrical roller bearings was established by ABAQUS software, through comparing the contact stress distribution of three kinds of modification curve(linear, circular-arc,logarithmic), it is found that the maximal contact stress of logarithmic crowned roller is the minimum, its stress distribute uniformly, and obvious stresses concentration phenomenon does not exist. This method provides a basis for improving the contact condition between rollers and raceways and improving the bearing capacity of bearings.

\section{Modification of Rolling Element}

\subsection{Modification Curve of Roller}

The design of roller modification includes the selection of roller generatrix modification curve and the determination of modification amount. The modification amount of roller has a direct impact on the lubricating. The most suitable generatrix type of roller should be designed according to the needs of bearing. According to the actual application of the bearing, it is necessary to ensure that the roller has effective contact length under light load, and there is no stress concentration at both ends of the roller under heavy load. The modification curve of roller includes partial arc shape, integral arc shape, logarithmic curve, etc.

The diagram of whole circular-arc shaped roller is shown in Figure 1, the center of the arc is located at bilateral symmetrical centerline, and the magnitude of its convex metric is related to the radius $\mathrm{R}$, the effective length $\mathrm{L}$ of roller, the convex metric $\Delta$. The curve equation is shown in Eq.(1).

$$
y(x)=R-\sqrt{R^{2}-x^{2}}
$$




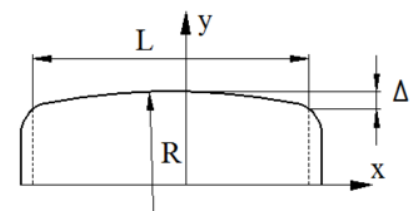

Figure 1. Whole circular-arc crowned

Gohar [14] improved the logarithmic modification method proposed by Lundberg equation, and made up the defect that the modification curve was discontinuous at both ends of the roller, the logarithmic modification equation is shown in Eq.(2).

$$
y=2 \cdot \frac{1-v^{2}}{\pi E} \cdot \frac{Q}{L} \cdot \ln \frac{1}{1-\left(1-\frac{0.6066 b}{L}\right) \cdot\left(\frac{2 X}{L}\right)^{2}} \quad\left(-\frac{L}{2}<X<\frac{L}{2}\right)
$$
element.

Where, $\mathrm{v}$ is Poisson's ratio, $\mathrm{E}$ is elastic modulus, $\mathrm{b}$ is the contact width of rolling

$$
\mathrm{b}=2\left(2 \frac{1-\mathrm{v}^{2}}{\pi \mathrm{E}} \frac{\mathrm{Q}}{\sum \rho \mathrm{L}}\right)^{1 / 2}
$$

$\sum \rho$ is the comprehensive curvature of the contact between the rolling body and the raceway.

$$
\sum_{D_{m} \text { is average diameter of roller. }} \rho=\frac{2 D_{m}}{\left(D_{m}-D_{w}\right) D_{w}}
$$

\subsection{Hertz Theoretical Contact Stress}

The contact state of the roller and ring is similar to the contact state of two parallel cylinders (as shown in Figure 2). L is the contact length. If the load Q is applied to the cylindrical generatrix and is linearly distributed uniformly, $q$ is the linear density of the load, $\mathrm{q}=\mathrm{Q} / \mathrm{L}$.

According to Hertz theory, the maximum contact stress of roller can be obtained by Eq.(3).

$$
p_{0}=\sqrt{\frac{2 q \sum \rho}{\pi\left(\frac{1-v_{1}^{2}}{E_{1}}+\frac{1-v_{2}^{2}}{E_{2}}\right)}}
$$

Where, $p_{0}$ is the maximum contact stress of roller, $v_{1}$ and $v_{2}$ are the Poisson's ratio of the material of the two contact bodies, $E_{1}$ and $E_{2}$ are the Young's modulus of the material of the two contact bodies.

The curvature radius of roller and inner ring is shown in Eq. (4). 


$$
\sum \rho_{\mathrm{i}}=\frac{1}{\mathrm{R}_{i}}+\frac{1}{R_{w}}
$$

The curvature radius of roller and outer ring is shown in Eq. (5).

$$
\sum \rho_{\mathrm{o}}=\frac{2}{\mathrm{R}_{\mathrm{o}}}-\frac{2}{R_{w}}
$$

Where, $R_{i}$ is curvature radius of inner ring, $R_{O}$ is curvature radius of outer ring.

If $\mathrm{Q}=3500 \mathrm{~N}$, the maximum contact stress can be calculated by the parameters of NJP3226X1 cylindrical roller bearing, $p_{0}=540.356 \mathrm{MPa}$.

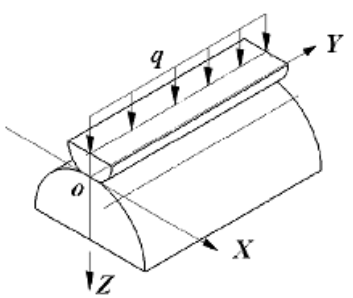

Figure 2. Line contact

\section{Finite Element Modeling}

Taking NJP3226X1 cylindrical roller bearing as the research object, the finite element analysis model of rolling bearings were established and the equivalent contact stresses between roller and the inner and outer ferrules was analyzed by ABAQUS. Main parameters of NJP3226X1 cylindrical roller bearing are shown in Table 1.

Table.1 Main parameters of double row cylindrical roller bearing

\begin{tabular}{l|l}
\hline Basic parameters & value \\
\hline Diameter of bearing inner and outer rings $(\mathrm{d} / \mathrm{D} / \mathrm{mm})$ & $130 / 240$ \\
\hline width $(\mathrm{B} / \mathrm{mm})$ & 160 \\
\hline Number of rollers Z(/ piece) & $16 \times 2$ \\
\hline Effective length of roller $(\mathrm{Lwe} / \mathrm{mm})$ & 48 \\
\hline Poisson's ratio & 0.3 \\
\hline Modulus of elasticity $(\mathrm{E} / \mathrm{GPa})$ & 208 \\
\hline Dynamic Load Rating $(\mathrm{Cr} / \mathrm{KN})$ & 28.4 \\
\hline Radial load(Fr/KN) & 5.68 \\
\hline
\end{tabular}

Firstly, the solid models of linear, circular and logarithmic cylindrical roller bearings are established by Pro/E, and then which is imported into ABAQUS software. The roller and rings are set to face to face contact, the coefficient of friction is set to 0.1 , the outer ring is fully constrained, symmetry constraint is adopted in the middle section of bearing, the radial load $\mathrm{Q}_{\max }=35 \mathrm{KN}$ was applied to the inner ring. 


\section{Result Analysis}

\subsection{Static Contact Stress Analysis}

The contact stress distribution of unmodified linear roller is shown in the Figure3, the maximum contact stress of roller surface appears at both ends of the rolling body, $\sigma_{\max }=511.6 \mathrm{MPa}$. The error between the finite element value and the theoretical value of the maximum stress is $5.33 \%$. The correctness of the finite element model is verified. There is a phenomenon of stress concentration at both ends and "edge effects", and the contact stress of the middle part of the roller is a smooth section, which is about 340MPa and is much smaller than the stress at both ends.
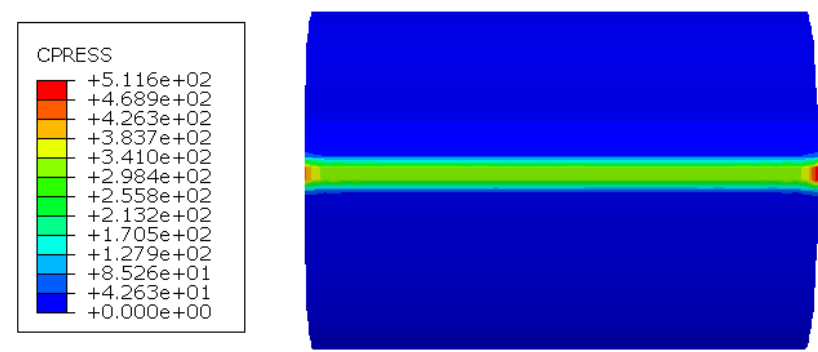

Figure 3. Contact stress of linear roller

The contact stress distribution of circular-arc crowned roller is shown in the Figure 4, $\sigma_{\max }=490.3 \mathrm{MPa}$, the maximum stress appears at the center of the contact area, its contact area showed a long striped rectangle, and the stress expands from the centre line point to both sides, with an decreasing tendency, which solves the "edge effect" of stress concentration at both ends.
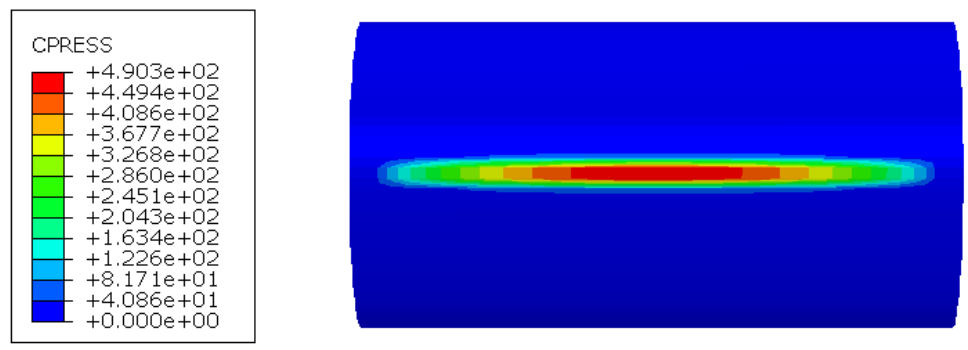

Figure 4. Contact stress of circular-arc crowned

The contact stress distribution of logarithmic crowned roller is shown in the Figure5.The stress at both ends of the roller is the minimum, the maximum stress occurs near the inner of both ends of the roller, $\sigma_{\max }=474.5 \mathrm{MPa}$. The stress concentration phenomenon did not appear, and the whole rolling element stressed uniformly. 

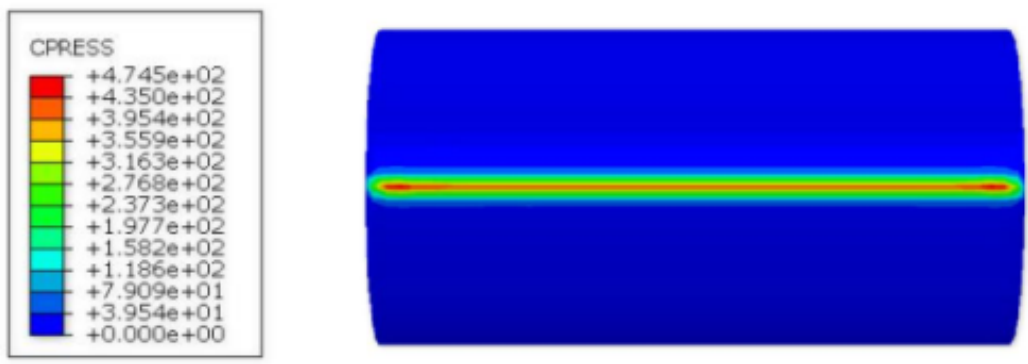

Figure 5. Contact stresses of logarithmic crowned roller

The contact stress distribution map of linear, circular-arc and logarithmic modified roller along the length direction of the roller are shown in the Figure6. Under three different modification conditions, the maximal contact stress of logarithmic modified roller is the minimum, its stress distribute uniformly, and obvious stresses concentration phenomenon does not exist, next is circular-arc modified roller, the stress at both ends is too small and the stress in the middle is too large, it can easily cause abrasion in the middle of the bearing, the linear roller has the highest contact stress, and there is an obvious stresses concentration phenomenon at both ends.

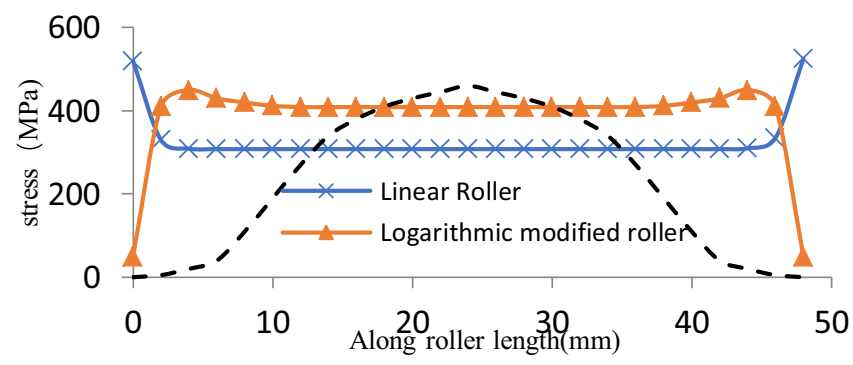

Figure 6. The contact stress distribution of three different crowned roller

In order to select the optimum convex metric of the logarithmic crowned roller, the following convex metric were selected as $0.030 \mathrm{~mm}, 0.032 \mathrm{~mm}$ and $0.034 \mathrm{~mm}$ respectively to establish the finite element model for analysis. The maximum contact stress of roller is shown in Table 2.

Through changing different logarithmic crowned convex metric, the optimum convex metric range of the bearing is about $0.030 \mathrm{~mm}$, and the modification amount is very small.

Table 2. The maximum contact stress of roller

\begin{tabular}{ccc}
\hline convex metric (mm) & Maximum stress(MPa) & Maximum stress reduction rate (\%) \\
\hline 0.030 & 452.9 & 11.46 \\
0.032 & 483.7 & 5.43 \\
0.034 & 509.4 & 0.20 \\
\hline
\end{tabular}




\subsection{Dynamic Contact Stress Analysis}

The dynamic finite element model of logarithmic modified roller was established, the modification amount is $0,03 \mathrm{~mm}$, the rotation speed of the inner ring and cage around the central axis is set at $1000 \mathrm{r} / \mathrm{min}$. The center node of the outer raceway at the maximum force is selected as the measuring point, the stress variation is shown in Figure7. It can be seen from Figure 7 that the contact stress is varies periodically. The difference of stress peak value is large, which is mainly due to roller slipping. The peak stress mainly depends on the load, and the cycle depends on the rotational speed. The roller slip should be reduced to reduce the variation of stress peak value.

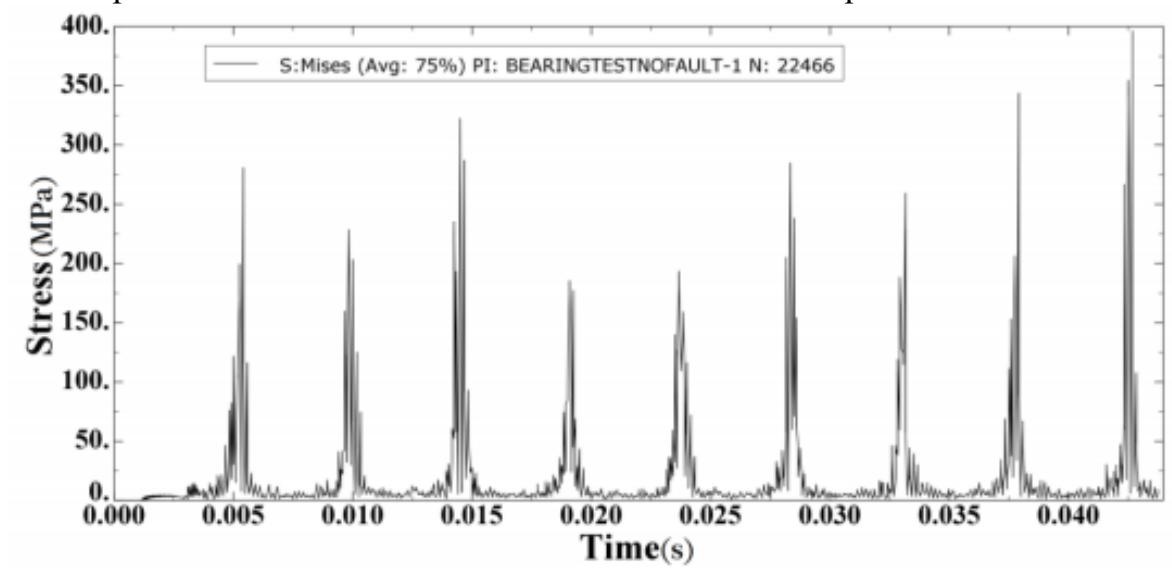

Figure 7. Equivalent stress with time

\section{Conclusions}

The finite element model of NJP3226x 1 cylindrical roller bearing of railway passenger cars is established under three kinds of modification curves rollers (linear, arc and logarithmic), it is found that the maximum contact stress of logarithmic modification roller is the smallest, and the stress distribution is uniform, without obvious stress concentration, the contact stress of the arc curved roller is small at both ends and large in the middle, the contact stress of straight-line roller is the largest, and there is obvious stress concentration at both ends. By analyzing the contact stress distribution of the logarithmic roller with different modification amount, the reasonable modification amount is about $0.030 \mathrm{~mm}$. The difference of stress peak value is large by the dynamic analysis. The contact stress of bearing changes periodically. This analysis provides a basis for improving the contact condition between roller and raceway and bearing capacity.

\section{Acknowledgement}

This work was supported by the Jiangxi education department project (Project No.GJJ180291 and GJJ170358). 


\section{References}

[1] Li GD, et al. Application development of cylindrical roller bearing for high-speed EMUs. ELECTRIC DRIVE FOR LOCOMOTIVES ,2018,1: 54-56.

[2] Chai JF, Jia XZ, Li JS. Finite element analysis on crowning of bearing rollerfor high speed railway passenger coach. Journal of Harbin Bearing,2008,29(4):1-3.

[3] Chen Xiaoyang. Optimization design of needle roller bearing and research on CAD technology. Shanghai University, 1989.

[4] Warda B, Chudzik A. Fatigue life prediction of theradial roller bearing with the correction of roller generators. International Journal of Mechanical Sciences, 2014, 89:299-310.

[5] Ramu B, Murthy VVR. Contact analysis of cylindrical rollerbearing using different roller profiles. IJRMET,2013,3 (1):29 -33.

[6] Fujiwara H, Kobayashi T, Kawase T, et al. Optimized logarithmic roller crowning design of cylindrical roller bearings and its experimental demonstration. Tribology Transactions, 2010, 53(6): 909-916

[7] Wei YY, Jiang JY. Unsymmetricshape modification of cylindrical roller bearing, mechanical design, 2003,20 (5): 17-19.

[8] Zhang LH, et al. Analysis on contact status of cylindrical roller bearings for railway passenger car axle box based on Romax, Journal of Harbin Bearing, 2017 (38) 1:3-7

[9] Zhang WH, Deng SE, Chen GD, et al. Study on the impact of roller convexity excursion of highspeed cylindrical roller bearing on roller's dynamic characteristics. Mechanism \& Machine Theory,2016,103:21- 39 .

[10] Yang F, Zhao J, Zhang LZ. Effect of roller profile modification on contact stress and life of cylindrical bearings. Mechanical Engineer, 2019,3:136-141.

[11] Zhang L. Finite. Analysis on hub bearing of heavy-loading trucks by FEM. Henan University of science and technology,2014.

[12] Xu H. Crown design of tapered roller bearings. Bearings, 2003, 9:6-7.

[13] Wang SF. Study on application of crowned profile on cylindrical rollers. Manufacturing Technology\&Machine Tool, 2004,7:91-92

[14] Johns PM, Gohar R. Roller bearings under radial and eccentric loads. Tribology International, 1981,14(3):131-136. 